ARTICLE

DOI: $10.1038 / s 41467-017-00574-9$

\title{
Lithium titanate hydrates with superfast and stable cycling in lithium ion batteries
}

Shitong Wang ${ }^{1,2}$, Wei Quan ${ }^{1}$, Zhi Zhu², Yong Yang ${ }^{3}$, Qi Liu ${ }^{4}$, Yang Ren ${ }^{4}$, Xiaoyi Zhang ${ }^{4}$, Rui Xu ${ }^{5}$, Ye Hong ${ }^{1}$, Zhongtai Zhang ${ }^{1}$, Khalil Amine ${ }^{5}$, Zilong Tang ${ }^{1}$, Jun Lu (i) ${ }^{5}$ \& Ju Li (iD) ${ }^{2,6}$

Lithium titanate and titanium dioxide are two best-known high-performance electrodes that can cycle around 10,000 times in aprotic lithium ion electrolytes. Here we show there exists more lithium titanate hydrates with superfast and stable cycling. That is, water promotes structural diversity and nanostructuring of compounds, but does not necessarily degrade electrochemical cycling stability or performance in aprotic electrolytes. As a lithium ion battery anode, our multi-phase lithium titanate hydrates show a specific capacity of about $130 \mathrm{~mA} \mathrm{~h}^{-1}$ at $\sim 35 \mathrm{C}$ (fully charged within $\sim 100 \mathrm{~s}$ ) and sustain more than 10,000 cycles with capacity fade of only $0.001 \%$ per cycle. In situ synchrotron diffraction reveals no 2-phase transformations, but a single solid-solution behavior during battery cycling. So instead of just a nanostructured intermediate to be calcined, lithium titanate hydrates can be the desirable final destination.

\footnotetext{
${ }^{1}$ State Key Lab of New Ceramics and Fine Processing, School of Materials Science and Engineering, Tsinghua University, Beijing 100084, China. ${ }^{2}$ Department of Nuclear Science and Engineering, Massachusetts Institute of Technology, Cambridge, Massachusetts 02139, USA. ${ }^{3}$ Department of Chemistry, Tsinghua University, Beijing 100084, China. ${ }^{4}$ X-ray Science Division, Advanced Photon Source, Argonne National Laboratory, Lemont, Illinois 60439 , USA. ${ }^{5}$ Chemical Sciences and Engineering Division, Argonne National Laboratory, Lemont, Illinois 60439, USA. ${ }^{6}$ Department of Materials Science and Engineering, Massachusetts Institute of Technology, Cambridge, Massachusetts 02139, USA. Correspondence and requests for materials should be addressed to Z.T. (email: tzl@tsinghua.edu.cn) or to J.L. (email: junlu@anl.gov) or to J.L. (email: liju@mit.edu)
} 
. ast-charging electronic devices have experienced dramatic development recently ${ }^{1}$. Compounds on the binary $\mathrm{Li}_{2} \mathrm{O}-\mathrm{TiO}_{2}$ composition line, such as $\mathrm{Li}_{4} \mathrm{Ti}_{5} \mathrm{O}_{12}$ $\left(2 \mathrm{Li}_{2} \mathrm{O} \bullet 5 \mathrm{TiO}_{2}, \mathrm{LTO}\right)$ and various $\mathrm{TiO}_{2}$ polymorphs (TO), are generally considered the most promising anode materials for Li-ion batteries in terms of rate capability and cycling stability, as well as the improved safety over graphite anode ${ }^{2-6}$. Producing nanostructured materials on the $\mathrm{Li}_{2} \mathrm{O}-\mathrm{TiO}_{2}$ composition line often requires water-based synthesis such as hydrothermal or sol-gel approaches, and thus one often deals with reaction intermediates that contain water (lithium titanate hydrates, LTHs) in the $\mathrm{Li}_{2} \mathrm{O}-\mathrm{TiO}_{2}-\mathrm{H}_{2} \mathrm{O}$ ternary composition space (Fig. 1). Because water is considered "harmful" in high-voltage window aprotic electrolytes (free water can be highly reactive to $\mathrm{LiPF}_{6}$, lithium metal anode and lithium alkyl carbonates) ${ }^{7}$, most researchers calcine the nanostructured LTHs to completely remove all water by raising temperature to above $500{ }^{\circ} \mathrm{C}^{8}$. However, this can cause an unwanted side effect of coarsening and aggregation of the structure. Herein, we demonstrate that the high-temperature calcining may not be necessary. One may only need to remove the more loosely bound water (such as adsorbed and crystallographic water) by heating to a much lower temperature of $<260{ }^{\circ} \mathrm{C}$, which does not induce significant coarsening of the nanostructure. The deeply trapped water inside LTHs, or pseudohydrates (i.e., hydroxide or hydroxonium ions or as $-\mathrm{OH}$ and $-\mathrm{H}$ groups $)^{9,10}$, does not necessarily degrade stability or performance in aprotic electrolytes, even with $\mathrm{H}_{2} \mathrm{O}$ : $\mathrm{TiO}_{2}$ molar ratio as high as 0.41 . Indeed, the trapped water can promote structural diversity and nanostructuring that could be highly beneficial for battery performance in aprotic electrolytes.

In this paper, a series of novel materials in the $\mathrm{Li}_{2} \mathrm{O}-\mathrm{TiO}_{2}-\mathrm{H}_{2} \mathrm{O}$ ternary composition space are discovered via an optimized dehydration induced nanostructuring (ODIN) approach, which is illustrated in Fig. 2 with an accompanying animation (Supplementary Movie 2). They show better electrochemical performances compared to all the $\mathrm{Li}_{2} \mathrm{O}-\mathrm{TiO}_{2}$ materials reported so far (see the comparison in Supplementary Table 1), including those after nanostructuring, doping and/or coating. As lithium ion battery anode, our novel lithium titanate hydrates can still show a specific capacity of about $130 \mathrm{~mA} \mathrm{~h}^{-1}$ at $\sim 35 \mathrm{C}$ (fully charged within $\sim 100 \mathrm{~s}$ ) and sustain more than 10,000 cycles with capacity fade of only $0.001 \%$ per cycle. This discovery indicates that the level of dehydration after hydrothermal or sol-gel synthesis should be carefully optimized, since phase transformation driven by dehydration could be a valuable tool for creating composites with nanostructure refinement, and mixed battery and pseudocapacitor features ${ }^{11}$, whereas complete dehydration by further heating can coarsen the structures and actually degrade electrochemical performances.

\section{Results}

Synthesis and characterization of lithium titanate hydrates. Two-dimensional (2D) crystals may provide kinetic advantage due to plenty of fast $\mathrm{Li}^{+}$conducting pathways ${ }^{12}$. We set out with layered hydrogen trititanates with a formula of $\mathrm{H}_{2} \mathrm{Ti}_{n} \mathrm{O}_{2 n+1} \cdot \mathrm{H}_{2} \mathrm{O}$ (or $\mathrm{Na}_{x} \mathrm{H}_{2-x} \mathrm{Ti}_{n} \mathrm{O}_{2 n+1} \cdot \mathrm{H}_{2} \mathrm{O}, 2 \leq n \leq 9, \quad 0 \leq x \leq 2$, due to the incomplete ionic exchange reaction), such as $\mathrm{H}_{2} \mathrm{Ti}_{2} \mathrm{O}_{5} \cdot \mathrm{H}_{2} \mathrm{O}$ $\left(2 \mathrm{H}_{2} \mathrm{O} \bullet 2 \mathrm{TiO}_{2}\right)$ and $\mathrm{H}_{2} \mathrm{Ti}_{3} \mathrm{O}_{7}\left(\mathrm{H}_{2} \mathrm{O} \bullet 3 \mathrm{TiO}_{2}\right)$, which are well known to form nanotubes and nanosheets ${ }^{8}$ but unable to support long-life electrochemical cycling in aprotic electrolyte. We then produced a $2 \mathrm{D} \quad \mathrm{Li}_{1.81} \mathrm{H}_{0.19} \mathrm{Ti}_{2} \mathrm{O}_{5} \cdot 2 \mathrm{H}_{2} \mathrm{O}$ precursor (hereafter referred to as LTHs-precursor) by hydrothermal lithiation of layered hydrogen trititanates in $\mathrm{LiOH}$ solution ${ }^{13}$, which preserves the layered nature with interlayer spacing of $0.8 \mathrm{~nm}$ (Supplementary Fig. 1). We then systematically study their performance in electrochemical cycling, as we gradually dehydrate the material (see the arrow direction in Fig. 1 and Supplementary Movie 1) by raising the heating temperature. TG (DSC) curves (Fig. 3a and Supplementary Fig. 2) and ex situ XRD patterns (Fig. 3b) reveal that the sample underwent three different stages in the ODIN process. The first weight loss region was $50-130^{\circ} \mathrm{C}$, which corresponded to the loss of absorbed water, and the second region was $130-190^{\circ} \mathrm{C}$, which was mainly attributed to the loss of crystallographic water, with LTHs-precursor

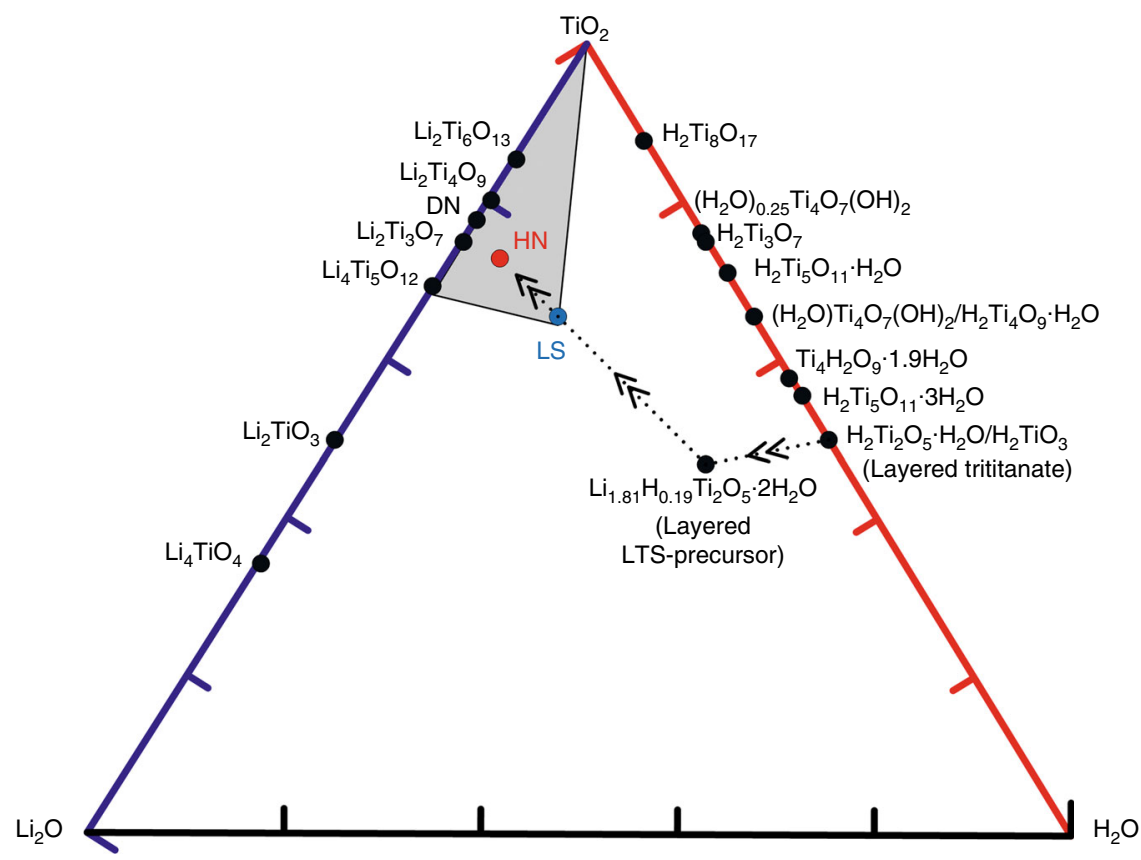

Fig. $1 \mathrm{Calculated}$ ternary phase diagram of $\mathrm{Li}_{2} \mathrm{O}-\mathrm{TiO}_{2}-\mathrm{H}_{2} \mathrm{O}$ ternary composition space. The arrow demonstrates the ODIN process, the black dot shows the common phase in the $\mathrm{Li}_{2} \mathrm{O}-\mathrm{TiO}_{2}-\mathrm{H}_{2} \mathrm{O}$ ternary composition space; and the blue dot is the new phase $\mathrm{LS}$; the shadow region illustrate the new mixed phase $\mathrm{HN}$ composed of $\mathrm{Li}_{4} \mathrm{Ti}_{5} \mathrm{O}_{12}-\mathrm{TiO}_{2}-\mathrm{LS}$. See also Supplementary Movie 1 


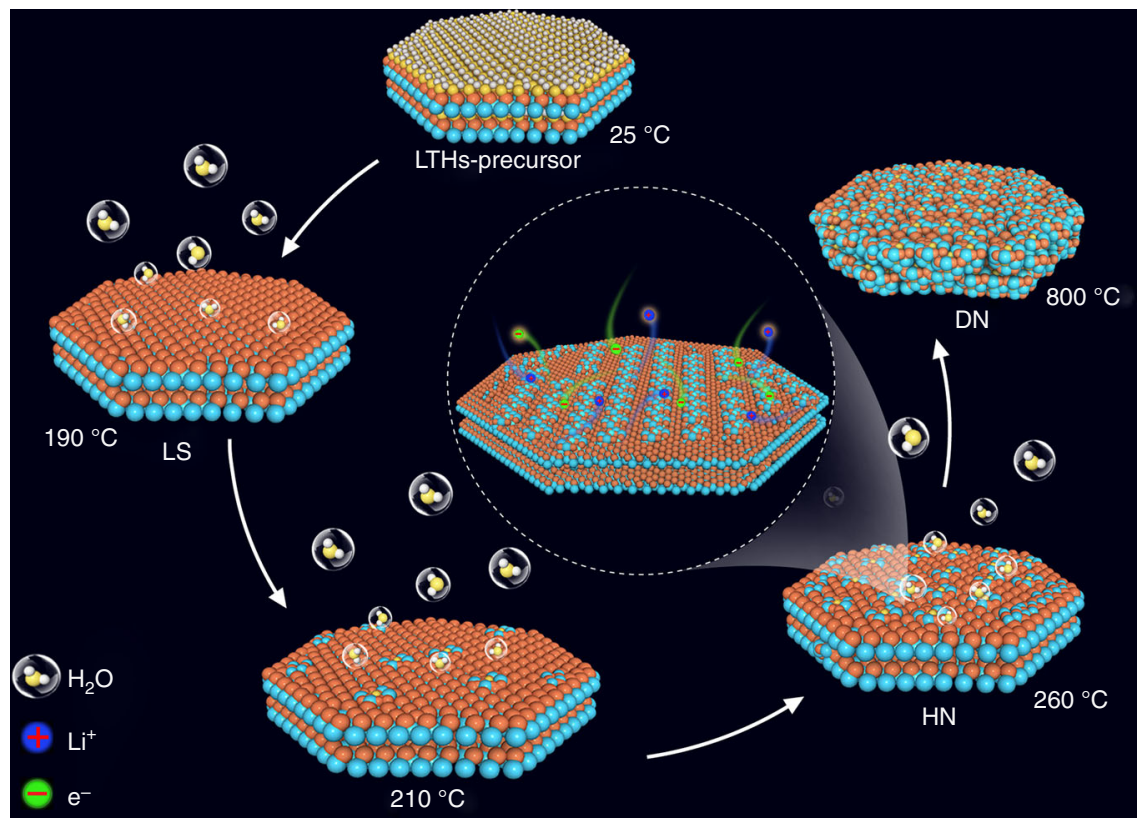

Fig. 2 Schematic diagram in the dehydration process and the fast lithium insertion/extraction within the hydrated nanocomposite (HN) material in battery. The tiny clusters appeared on the nanosheet after $190^{\circ} \mathrm{C}$ represent LTO and TO nanocrystallites, and the clusters grow gradually to bigger crystals with the increase of temperature

transforming into a new layered structure, hereon called LS. In situ high-energy X-ray diffraction (HEXRD, Fig. 3c) technique illustrated the transformation of the layered structure. During the thermal ramping, the reflection of layered structure (200) for LTHs-precursor maintained until $\sim 180^{\circ} \mathrm{C}$, and then shifted to a higher $2 \theta$ angle at above $190^{\circ} \mathrm{C}$, leading to the decrease of interlayer spacing to $0.6 \mathrm{~nm}$ (Supplementary Fig. 3). Fourier transform infrared spectroscopy (FTIR) demonstrates that the main state of proton in LS is hydrogen-bonded $\mathrm{Ti}-\mathrm{OH}$ (Supplementary Fig. 4). A possible chemical formula of LS is $\mathrm{Li}_{1.25} \mathrm{H}_{1.63} \mathrm{Ti}_{2} \mathrm{O}_{5.44-\sigma}$ ( $\sigma$ represents the $\mathrm{O}$ vacancy), based on inductively coupled plasma mass spectroscopy (ICP-MS) and elemental analyzer measurements. Prior to the formation of LS (before dehydrating to $190^{\circ} \mathrm{C}$ ), the electrochemical performance of dehydrated LTHs-precursor is not satisfactory, because the "free water" can be driven out of the material during electrochemical cycling and therefore severely degrade the aprotic electrochemical system (Supplementary Fig. 5) as previously understood ${ }^{7}$.

The last weight loss region was $190-400{ }^{\circ} \mathrm{C}$, which corresponded to the gradual collapse of the layered structure and the growth of three-dimensional (3D) LTO and TO nanocrystallites via a topotactic transformation reaction ${ }^{14,} 15$. With rising temperature in this regime, an increasing proportion of $\mathrm{Li}_{4} \mathrm{Ti}_{5} \mathrm{O}_{12}$ and anatase $\mathrm{TiO}_{2}$ nanocrystallites was obtained (as shown in the yellow region and green region in Fig. 3b, respectively); correspondingly, the proportion of LS decreased (as shown in the purple region in Fig. 3b), and the material became more defective due to loss of water in the 2D lattice. Notably, the peak corresponding to the interlayer spacing of LS disappeared above $350{ }^{\circ} \mathrm{C}^{8}$, implying the collapse of layered structure. As the temperature reached $400{ }^{\circ} \mathrm{C}$, the diffraction peaks of $\mathrm{Li}_{4} \mathrm{Ti}_{5} \mathrm{O}_{12}$ and $\mathrm{TiO}_{2}$ became steep, indicating growth of $3 \mathrm{D}$ crystals. To make our point of pseudohydrates being benign for room-temperature (RT) electrochemical performance, we pick a final dehydration temperature of $260^{\circ} \mathrm{C}$, where a nanocomposite material consisting of defective LS, spinel $\mathrm{Li}_{4} \mathrm{Ti}_{5} \mathrm{O}_{12}$ (JCPDS No. 49-0207) and anatase $\mathrm{TiO}_{2}$ (JCPDS
No. 89-4921) nanocrystallites was obtained, with the individual sets of planes indexed (Supplementary Fig. 6). We call this material the hydrated nanocomposite (HN) state, which still contains significant amount of water in its defected LS component to keep the layered structure, albeit less than LS as illustrated in Fig. 1. The chemical formula of $\mathrm{HN}$ is $\mathrm{Li}_{1.39} \mathrm{H}_{1.18} \mathrm{Ti}_{2} \mathrm{O}_{5.29-\sigma}(\sigma$ represents the $\mathrm{O}$ vacancy) based on the same measurements for LS. It is important to note that the hydrogen atoms are distributed homogeneously throughout the bulk of the nanosheets from time-of-flight secondary ion mass spectrometry (TOF-SIMS) depth profile (Supplementary Fig. 7), distinct from surface hydrogenation ${ }^{16}$.

Beyond $400{ }^{\circ} \mathrm{C}$, no more water came out. The final product at $800^{\circ} \mathrm{C}$ is $\mathrm{Li}_{4} \mathrm{Ti}_{5} \mathrm{O}_{12}$ and rutile $\mathrm{TiO}_{2}$ (JCPDS No. 21-1276), as anatase $\mathrm{TiO}_{2}$ transformed to rutile $\mathrm{TiO}_{2}$ at a relatively high temperature of $800{ }^{\circ} \mathrm{C}$. This completely water-free $\mathrm{Li}_{4} \mathrm{Ti}_{5} \mathrm{O}_{12}-\mathrm{TiO}_{2}$ nanocomposite (hereafter referred to as $\mathrm{DN}$, dry nanocomposite) is also measured for RT electrochemical performances for comparison. Note that $\mathrm{DN}$ (which is the route most researchers took to obtain electrodes on $\mathrm{Li}_{2} \mathrm{O}-\mathrm{TiO}_{2}$ composition axis after hydrothermal synthesis) has coarser structures than $\mathrm{HN}$, due to coarsening and aggregation at higher temperatures (Supplementary Figs. 8, 10). The specific surface area decrease caused by the coarsening is also characterized by $\mathrm{N}_{2}$ adsorption/desorption (Supplementary Fig. 11). This tradeoff between "water removal" and "nanostructure coarsening" and its impact on electrochemical performance is at the heart of the current work. We will show that removing all water is often an overkill. Instead, the as-synthesized LS and HN through ODIN give the best results.

Electrochemical behavior of lithium titanate hydrates. Electrochemical performance of hydrated LS and HN materials were evaluated and compared to water-free DN. Figure 3d provides the galvanostatic discharge/charge curves of HN, LS and $\mathrm{DN}$ at a current density of $100 \mathrm{~mA} \mathrm{~g}^{-1}$ between 1.0 and $2.5 \mathrm{~V}$. LS has a discharge capacity of $174 \mathrm{~mA} \mathrm{~h} \mathrm{~g}^{-1}$ and the nearly constant 
a

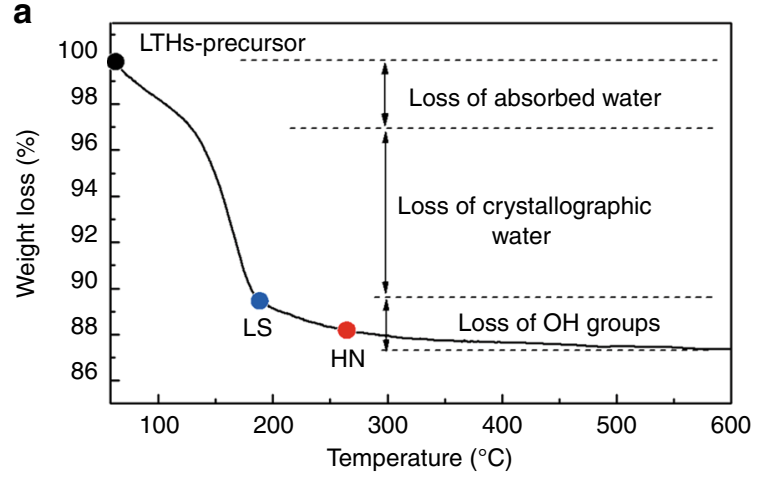

b

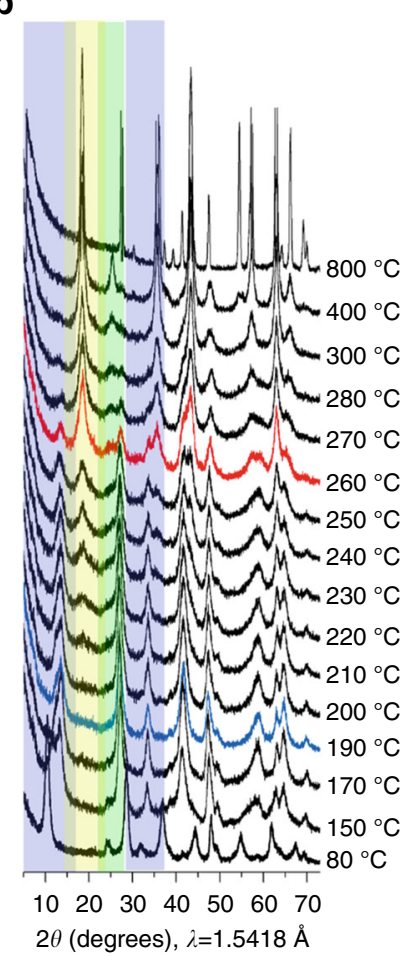

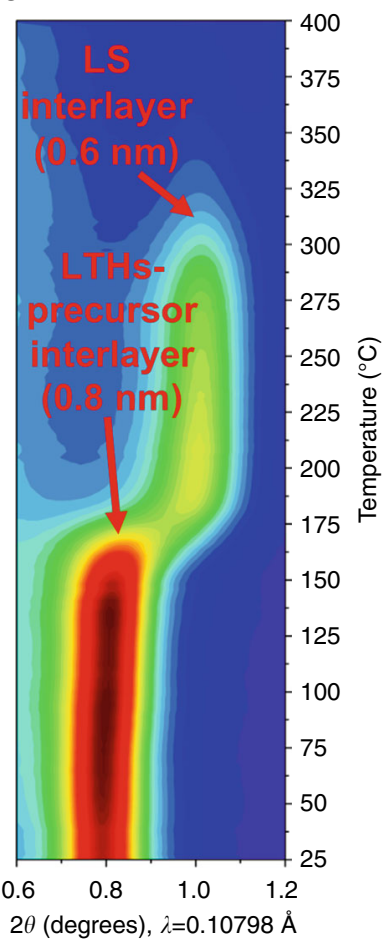

d

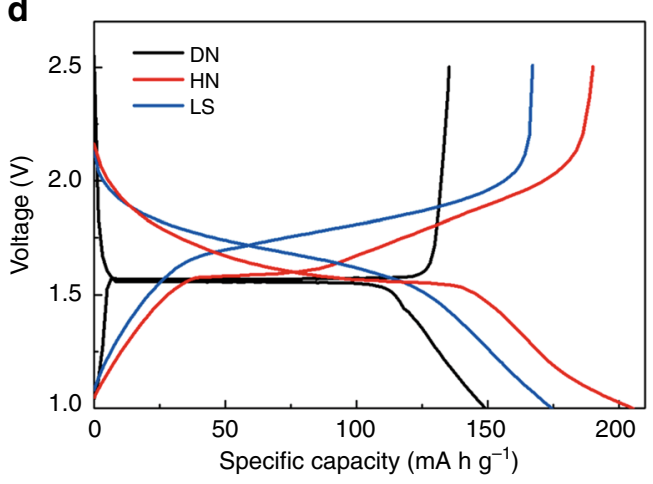

e
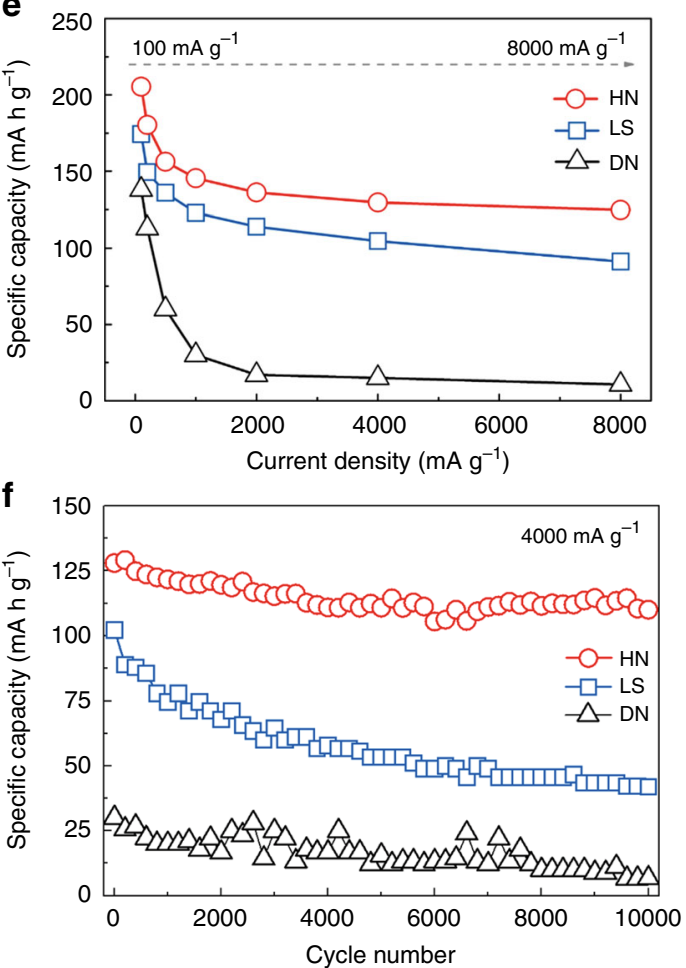

Fig. 3 Characterization of as synthesized materials in the $\mathrm{Li}_{2} \mathrm{O}-\mathrm{TiO}_{2}-\mathrm{H}_{2} \mathrm{O}$ ternary space. a TG analysis; $\mathbf{b}$ Ex situ XRD patterns and (c) contour plot of in situ HEXRD profile (red represents a high intensity and blue represents a low intensity) of LTHs-precursor heated to different temperatures. Comparison among $\mathrm{LS}, \mathrm{HN}$ and DN electrode materials in the following three cases: $\mathbf{d}$ Charge-discharge profiles at $100 \mathrm{~mA} \mathrm{~g}^{-1}$ between 1.0 and $2.5 \mathrm{~V}$ (vs Li/Li ${ }^{+}$); e Rate capabilities at different current densities from 200 to $8000 \mathrm{~mA} \mathrm{~g}^{-1}$ and $\mathbf{f}$ cycling stability at $4000 \mathrm{~mA} \mathrm{~g}^{-1}$. All RT electrochemical measurements d-f were carried out in two-electrode 2032 coin-type half-cells

slope of current-potential curve indicates a quasi-solid-solution behavior. On the other hand, DN reveals a typical battery type of discharge curve with a well-defined voltage plateau and delivers $149 \mathrm{~mA} \mathrm{~h} \mathrm{~g}^{-1}$ discharge capacity. HN, with a discharge storage behavior combining the features of the following three: sloping current-potential for LS, nanosized LTO and TO ${ }^{17,18}$, as well as the additional Li storage at the interfaces, exhibiting high capacity of $205 \mathrm{~mA} \mathrm{~h} \mathrm{~g}^{-1}$. Cyclic voltammetry (CV) curves for LS, HN and $\mathrm{DN}$ materials further demonstrate the composite nature of $\mathrm{HN}$ electrode (Supplementary Fig. 12).

The rate capability of the three materials is shown in Fig. 3e. When discharged at $100 \mathrm{~mA} \mathrm{~g}^{-1}$, owing to the surface reactions of LS together with the additional $\mathrm{Li}$ storage at the interfaces among $\mathrm{Li}_{4} \mathrm{Ti}_{5} \mathrm{O}_{12}-\mathrm{TiO}_{2}$-LS, $\mathrm{HN}$ delivers a reversible capacity of $205 \mathrm{~mA} \mathrm{~h} \mathrm{~g}^{-1}$, which is higher than LS $\left(174 \mathrm{~mA} \mathrm{~h} \mathrm{~g}^{-1}\right)$ or DN $\left(138 \mathrm{~mA} \mathrm{~h} \mathrm{~g}^{-1}\right)$. As the current density increases to $8000 \mathrm{~mA} \mathrm{~g}^{-1}$, the capacity of HN and LS gently decrease to $124 \mathrm{~mA} \mathrm{~h} \mathrm{~g}^{-1}$ and
$91 \mathrm{~mA} \mathrm{~h}^{-1}$, respectively, which demonstrate their superior rate capabilities. The capacity of $\mathrm{DN}$, in contrast, plummets to $17 \mathrm{~mA} \mathrm{~h} \mathrm{~g}^{-1}$ at $2000 \mathrm{~mA} \mathrm{~g}^{-1}$ and ends in almost zero at higher current density. As a result, LS demonstrates a quite stable performance for ultrafast lithium ions insertion/extraction at a high current rate of $8000 \mathrm{~mA} \mathrm{~g}^{-1}$ ( $70 \mathrm{C}$ ) for 1000 cycles with $76 \%$ capacity retention of its initial capacity $106 \mathrm{~mA} \mathrm{~h} \mathrm{~g}^{-1}$ (Supplementary Fig. 13). The $\mathrm{HN}$ electrode exhibits superior cycling capacity of about $130 \mathrm{~mA} \mathrm{~h} \mathrm{~g}^{-1}$ at $4000 \mathrm{~mA} \mathrm{~g}^{-1}$ (fully charged within $\sim 100 \mathrm{~s}$ ) and sustains $>10,000$ cycles with $86 \%$ capacity retention (Fig. 3f). Moreover, nearly complete nanosheet morphology of $\mathrm{HN}$ was retained after 10,000 ultrafast cycling under transmission electron microscopy (TEM; Supplementary Fig. 14) observation. From X-ray photoelectron spectroscopy (XPS) analysis of the electrodes after cycling (Supplementary Fig. 15), we know that $\mathrm{Li}_{2} \mathrm{CO}_{3}$ and ROCOOLi species are the major components on the surface of LS and HN electrodes, due to 

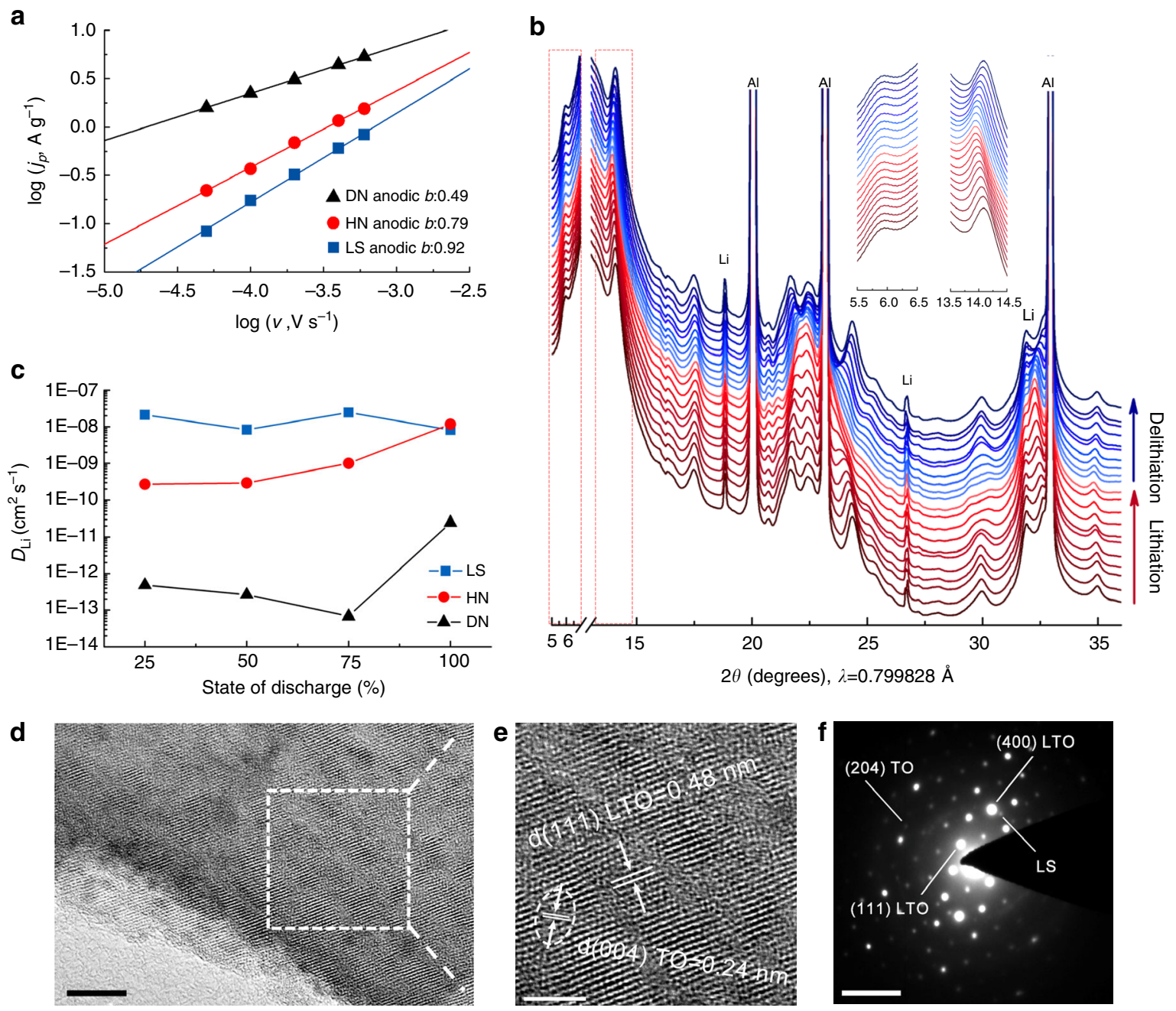

Fig. 4 Illustration for electrochemical performance enhancement mechanism of lithium titanate hydrates. $\mathbf{a}, b$-values determination of anodic peaks with sweep rate from $0.05 \mathrm{mV} \mathrm{s}^{-1}$ to $0.6 \mathrm{mV} \mathrm{s}^{-1}$ for LS, $\mathrm{HN}$ and DN electrodes; $\mathbf{b}$ in situ synchrotron XRD results during the third cycle of LS electrode cycled at $100 \mathrm{~mA} \mathrm{~g}^{-1}$, some main peaks of $\mathrm{LS}$ at $6^{\circ}$ and $14^{\circ}$ are highlighted in the insert; $\mathbf{c}$ Li-ion diffusion coefficient at various state of discharge; $\mathbf{d}$ HRTEM image of a $\mathrm{HN}$ nanosheet (scale bar, $10 \mathrm{~nm}$ ) and $\mathbf{e}$ Magnified image of the selected region in $\mathbf{d}$ with a spacing of $0.48 \mathrm{~nm}$ of $\mathrm{Li}_{4} \mathrm{Ti}_{5} \mathrm{O}_{12}$ and $0.24 \mathrm{~nm}$ of $\mathrm{TiO}_{2}(\mathrm{scale}$ bar, $5 \mathrm{~nm}$ ); f SAED pattern of HN (scale bar, $51 / \mathrm{nm}$ )

the interfacial reactions between the electrodes and electrolyte, but with little influence on their performance ${ }^{19}$. The high rate capacity of DN at $4000 \mathrm{~mA} \mathrm{~g}^{-1}$, in contrast, drops rapidly to $<20 \mathrm{~mA} \mathrm{~h} \mathrm{~g}^{-1}$ for the first 500 cycles, and failed completely after 1000 cycles. In terms of mass loading, rate and cyclability (see comparison with literatures in Supplementary Table 1), the $\mathrm{HN}$ and LS are two very promising materials (both hydrated) for fast-charging Li-ion batteries or even supercapacitors.

The charge storage mechanism was characterized by sweep voltammetry (Supplementary Fig. 18), assuming that the current obeys a power-law relationship with the sweep rate (Fig. 4a): $:^{11,12}$

$$
i=a v^{b}
$$

where $a$ and $b$ are adjustable parameters. For LS, $b$-value is 0.92 , close to 1 , indicating that the electrochemical kinetics is mainly generalized surface-controlled redox reaction. The $b$-value of $\mathrm{DN}$, on the other hand, approaches a value of 0.5 (diffusion-controlled redox reaction). HN, as a combination of high-rate feature for faradic pseudocapacitance (LS) and high-capacity feature for diffusion-controlled process $\left(\mathrm{Li}_{4} \mathrm{Ti}_{5} \mathrm{O}_{12}\right.$ and $\left.\mathrm{TiO}_{2}\right)$, presents an intermediate $b$-value of 0.79 , and leads to the best capacity/cyclability combination (Supplementary Table 1).
The structural transformation of LS at different stages of extraction-insertion was examined via in situ synchrotron diffraction (Fig. 4b) at Argonne's Advanced Photon Source, demonstrating a solid-solution behavior ${ }^{20}$ over a large concentration range. No two-phase transformation was detected, which involves changes of peak heights at distinct locations. The lattice constant (peak position) is seen to change linearly and reversibly with the state of charge. The change of interlayer spacing corresponding to $\sim 6^{\circ}$ is quite small, implying a fast transport kinetics of $\mathrm{Li}^{+}$through the layered structure. It is known that the solid solution behavior could emerge when increasing the (dis)charge rate or decreasing the particle size ${ }^{20,21}$. Consequently, the fact that solid solution behavior appeared at relatively low current density $(<0.5 \mathrm{C})$ suggests that the electrode may possess good potential in achieving super high-rate capability ${ }^{12,} 22,23$. The Li-ion diffusion coefficients $\left(D_{\mathrm{Li}}\right)$ of the three electrodes at different discharge depths are shown in Fig. 4c (see more details in Supplementary Table 4 and Supplementary Figs. 20, 22). The Li-ion diffusivity in LS $\left(8.21 \times 10^{-9}-2.46 \times 10^{-8} \mathrm{~cm}^{2} \mathrm{~s}^{-1}\right)$ is about 3-5 orders of magnitude higher than that in DN $\left(6.81 \times 10^{-14}-2.46 \times 10^{-11} \mathrm{~cm}^{2} \mathrm{~s}^{-1}\right)$. This tremendous difference is attributed to the nanostructure coarsening of DN and 2D layered structure of LS, which makes LS 

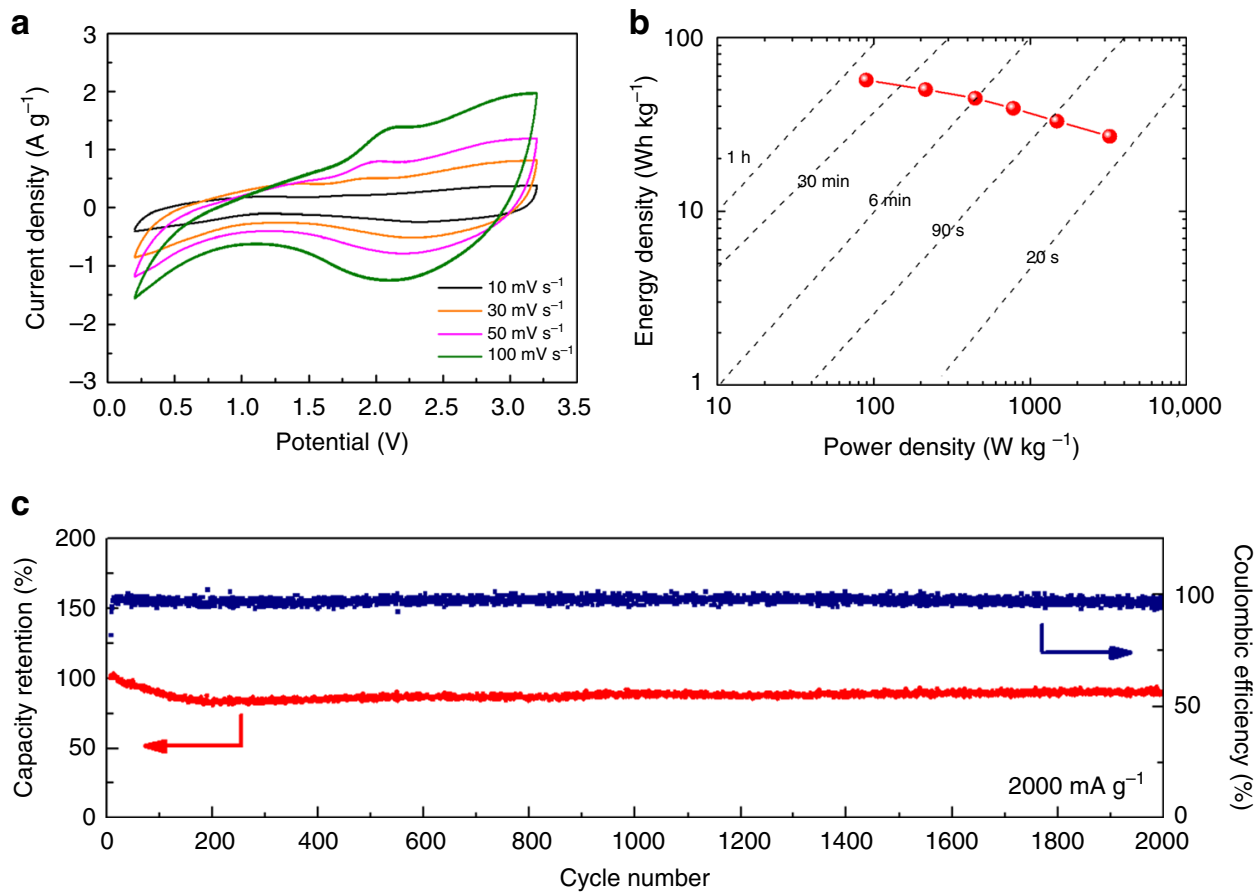

Fig. 5 Electrochemical performance of hybrid supercapacitor using an activated carbon (AC) and hydrated nanocomposite (HN) composite. a, CV curves in various scan rates from 10 to $100 \mathrm{mV} \mathrm{s}^{-1} ; \mathbf{b}$, Ragone plots of power density vs. energy density, based on the total mass of active materials in both electrodes; c, Cycle stability and Coulombic efficiency at a current density of $2000 \mathrm{~mA} \mathrm{~g}^{-1}$

a fast ion conductor. Just as shown in the animation and Fig. 4d, $\mathrm{e}$, the $\mathrm{HN}$ was composed of uniformly dispersed $\mathrm{Li}_{4} \mathrm{Ti}_{5} \mathrm{O}_{12}$ and $\mathrm{TiO}_{2}$ crystallites about $2-5 \mathrm{~nm}$ on a LS nanosheet. Besides, the thickness of the $\mathrm{HN}$ nanosheets is only about $5 \mathrm{~nm}$ via atomic force microscope (AFM) analysis (Supplementary Fig. 23). Lattice fringes of anatase $\mathrm{TiO}_{2}$ (004) plane and $\mathrm{Li}_{4} \mathrm{Ti}_{5} \mathrm{O}_{12}$ (111) plane with a $40^{\circ}$ angle are observed in Fig. 3d. Similarly, lattice fringes of anatase $\mathrm{TiO}_{2}$ (004) plane and LS plane with a $28^{\circ}$ angle (Supplementary Fig. 24) are also discovered. In selected-area electron diffraction pattern (SAED, Fig. 4f), the HN composite material was constituted by a set of sharp spots corresponding to (111), (311) and (400) planes of $\mathrm{Li}_{4} \mathrm{Ti}_{5} \mathrm{O}_{12}$, some weak spots corresponding to (204) planes of anatase $\mathrm{TiO}_{2}$ and unknown planes of $\mathrm{LS}$, proving that it is a combination of LS and $\mathrm{Li}_{4} \mathrm{Ti}_{5} \mathrm{O}_{12}$ monocrystals with minor amount of anatase $\mathrm{TiO}_{2}$ monocrystals. As ion conductivity can be greatly enhanced by the space charge and percolation ${ }^{24}$, hybrid nanostructured $\mathrm{HN}$ can exhibit outstanding Li-ion diffusion coefficients $\left(2.72 \times 10^{-10}-1.17 \times 10\right.$ $\left.-8 \mathrm{~cm}^{2} \mathrm{~s}^{-1}\right)$.

$\mathrm{HN}$ composite (consisting of LS/LTO/TO mixture) during battery cycling was also examined using in situ synchrotron diffraction. In Supplementary Fig. 25, the diffraction peaks of the LS component show a continuous shift in small range during the lithiation/delithiation process, which demonstrates a solid-solution behavior. Interestingly, no obvious two-phase transitions were found in the in situ XRD pattern of the LTO and TO components either. It is well known that the redox mechanism of bulk LTO and TO involves two-phase transformations ${ }^{17}, 18,25$. However, when the particle size decreases to several nanometers $(<5 \mathrm{~nm})$, many electrode materials with two-phase behavior will change to solid-solution behavior, showing a single solid-solution (such as regular solution model with nonzero enthalpy of mixing) phase field with large solubility range for $\mathrm{Li}^{26}, 27$. This would allow skipping the nucleation-and-growth kinetics of two-phase transformations, which involves an interfacial energy plus surface energy penalty that could be too expensive and slow for small particles undergoing fast changes. Here, the capacitor-like behavior indeed demonstrates the nano-size effect of our $\mathrm{HN}$ nanocomposite material as well as the advantages of ODIN strategy, which leads to the best electrode with super high-rate capability.

ODIN is a simple approach to obtain sub-10 nm LTO/TO crystallites firmly anchored on LS. While nanocrystallites could more easily accommodate the structural changes during the ultrafast insertion and extraction process for the cycling stability improvement ${ }^{28}$, a major problem is the aggregation of nanocrystallites during preparation and battery cycling 29 . The LS substrate plays a crucial role in structural anchoring to restrict the growth and prevent the aggregation of LTO and TO nanograins during RT battery cycling, thus making the ultrastable performance of $\mathrm{HN}$ possible. Lattice distortion and disorder in $\mathrm{HN}$ composite at the interfaces among LTO-TO-LS (Fig. 4e and Supplementary Fig. 26) and some disordered protons located in the interface layer (detected by ${ }^{1} \mathrm{H}$ solid state magic-angle spinning nuclear magnetic resonance (MAS-NMR), Supplementary Fig. 27) may provide more active sites for Li storage and more crystal defects for conductivity improvement ${ }^{30-32}$. In addition, when the size of a crystal decrease to several nanometers, not only is the diffusion distance of lithium ions shortened ${ }^{33}$, the local material properties could even change as well ${ }^{34,35}$, which might greatly enhance the ionic and electrical conductivity of the crystal.

To demonstrate the practical utility of $\mathrm{HN}$ anode, we tested the electrochemical performance of hybrid supercapacitor using the commercial activated carbon (AC, YP-50F by Kuraray Chemical Co., LTD) and HN composite at an optimal mass ratio of $m_{\text {positive }} / m_{\text {negative }}=3: 1$, between 0.2 and $3.2 \mathrm{~V}$. Different from the symmetric supercapacitor, the $\mathrm{AC} / \mathrm{HN}$ hybrid supercapacitor exhibits a gradual deviation from the ideal rectangular shape with increasing scan rate (Fig. 5a), owing to the overlapping of two different energy-storage mechanisms. The Ragone plot (Fig. 5b), which exhibits the trade-off between energy and power densities 
in the hybrid supercapacitor, was calculated from the cyclic voltammograms using the equations of Zhang $\mathrm{et}^{3 l^{36}}$. (the energy density and power density were based on the total mass of active materials in both electrodes). The hybrid supercapacitor not only could deliver up to $57 \mathrm{Wh} \mathrm{kg}^{-1}$ at relatively low-power density $\left(90 \mathrm{~W} \mathrm{~kg}^{-1}\right)$, but also could maintain $27 \mathrm{Wh} \mathrm{kg}^{-1}$ with an extremely high-power density of about $3200 \mathrm{~W} \mathrm{~kg}^{-1}$ (fully charged within $30 \mathrm{~s}$ ). It also exhibited an ultrastable cycling performance (2000 cycles with capacity fade of only $5 \times 10^{-3} \%$ per cycle) under a current density of $2000 \mathrm{~mA} \mathrm{~g}^{-1}$ (Fig. 5c), proving its ultrafast transport of both $\mathrm{e}^{-}$and $\mathrm{Li}^{+}$in aprotic electrolyte systems (Supplementary Movie 3). In addition, we have also assembled full batteries with $\mathrm{LiFePO}_{4}$ cathode vs. HN anode (Supplementary Fig. 28), with tolerable gassing. The excellent cyclability of the full cell validates LTHs as promising electrode materials for the real-life fast-charging electronics and electric vehicles.

\section{Discussion}

In summary, we have discovered a series of novel lithium titanate hydrates in the $\mathrm{Li}_{2} \mathrm{O}-\mathrm{TiO}_{2}-\mathrm{H}_{2} \mathrm{O}$ ternary composition space. The LTHs exhibit outstanding high-rate performance, and even more intriguingly, extraordinary RT cycling stability. Once we realize that not all water is bad, and some water can actually do good, it might be possible to synthesize many more electrode materials with superior power density and ultralong cycle life in the $\mathrm{Li}_{2} \mathrm{O}-\mathrm{TiO}_{2}-\mathrm{H}_{2} \mathrm{O}$ composition space, that beat what are available on the $\mathrm{Li}_{2} \mathrm{O}-\mathrm{TiO}_{2}$ binary axis (the "dry" side), by taking advantages of the structural diversity of hydrated crystals (2D layered), and dehydration induced phase transformation and nanostructure refinement.

The ODIN approach may be generalized to other hydrated compound composition spaces as well. The materials design philosophy we have established is the following: (i) water may not be bad actor for RT electrochemical cycling in aprotic electrolyte, if they are trapped in the lattice and not free (our empirical evidence is that the TG desorption temperature should be above $190^{\circ} \mathrm{C}$ or so); (ii) as water promotes structural diversity in hydrothermal or sol-gel process, it could be used to tailor the initial structures such as 2D sheets or nanotubes, which greatly improves the ion diffusivity; (iii) the dehydration process thereafter should be carefully optimized: first, all the "free" water (adsorbed, crystallographic) should be driven out; but as it is not integral part of the lattice, this usually does not cause drastic phase change. Then as temperature is further raised, some pseudohydrates embedded in the lattice are also partially driven out; as they were strongly embedded in the lattice, their partial removal can cause drastic phase transformation. This is actually a golden opportunity to refine the nanostructures, as the old structure is being dismantled and turned into a defected form, and new phases are nucleated as nanocrystals, which must start out very small by definition. These sub- $10 \mathrm{~nm}$ new phases are well-anchored on the $2 \mathrm{D}$ substrate, providing structural stability during high-rate RT cycling, as well as a hybrid supercapacitor-battery kinetics and the best capacity/rate/ cyclability combination. Because of this, we believe in many occasions after hydrothermal or sol-gel processing, there could exist an optimal dehydration temperature $T_{\text {optimal }}$ for achieving the best RT electrochemical performance. Further drying the system above $T_{\text {optimal }}$ will be counter-productive, since the nanostructures could (i) aggregate and coarsen, (ii) or change from $2 \mathrm{D}$ to $3 \mathrm{D}$ forms, as we showed for the case of $\mathrm{DN}$, where not only the rate capability degrades, but also the cyclability. As ubiquitous water is in nature and in chemical synthesis, we believe the ODIN synthetic approach could provide a window of opportunity for finding new high-performance electrode materials in aprotic electrolyte systems.

\section{Methods}

Materials synthesis. A typical preparation procedure of lithium titanate hydrates consists of three steps. First, layered hydrogen trititanate was prepared via hydrothermal reaction between anatase $\mathrm{TiO}_{2}$ powders and concentrated $\mathrm{NaOH}$ solution at $150{ }^{\circ} \mathrm{C}$ for several hours, followed by ion substitution of $\mathrm{Na}^{+}$with $\mathrm{H}^{+}$in $0.5 \mathrm{M} \mathrm{HNO}_{3}$ solution for $3 \mathrm{~h}$. Second, layered LTHs-precursor was obtained by chemical lithiation of hydrogen trititanate in a $0.8 \mathrm{M} \mathrm{LiOH}$ solution heated at $150^{\circ}$ $\mathrm{C}$ for $12 \mathrm{~h}$ in a Teflon-lined stainless steel autoclave. Thirdly, a series of lithium titanate hydrates were synthesized by drying the LTHs-precursor at various temperatures ranging from 80 to $400{ }^{\circ} \mathrm{C}$ for $3 \mathrm{~h}$ in a vacuum. In this article, LS and $\mathrm{HN}$ were obtained at 190 and $260^{\circ} \mathrm{C}$, respectively. For comparison, we chose $800^{\circ} \mathrm{C}$ as the synthesis temperature for $\mathrm{DN}$, and kept the other heating experimental variables fixed.

Materials characterization. Ex situ powder X-ray diffraction (XRD) was recorded on a Bruker D8 Advance with $\mathrm{Cu} \mathrm{K} \alpha$ radiation $(\lambda=1.5418 \AA)$. In situ XRD measurements were carried out at 11-ID-C beamline (for the dehydration process of LTHs-precursor and the charge and discharge process of HN) and 11-ID-D beamline (for the charge and discharge process of LS) at Advanced Photon Source, Argonne National Laboratory. Scans were collected in transmission mode using fixed wavelengths of $0.10798 / 0.117418$ and $0.799828 \AA$ for 11 -ID-C beamline and 11-ID-D beamline, respectively. The $2 \mathrm{D}$ patterns were calibrated and converted to the conventional 1D format (intensity vs. 2 theta) by using the GSAS-II program. The data are plotted and analyzed by using Bachir Aoun's Ranked Data Analysis program $^{37}$. For the dehydration, the LTHs-precursor was heated up to $400{ }^{\circ} \mathrm{C}$ with a heating rate of $2{ }^{\circ} \mathrm{C} \mathrm{min}{ }^{-1}$ and a spectrum data collection rate of one pattern every $60 \mathrm{~s}$. For the charge and discharge process, a coin-cell with a hole for beam path was assembled using the same electrode and electrolyte mentioned below. Thermogravimetric-differential scanning calorimetry (TG-DSC) analysis was carried out using NETZSCH-STA $449 \mathrm{~F} 3$ with a heating rate of $2{ }^{\circ} \mathrm{C} \mathrm{min}{ }^{-1}$ under a continuous flow of $\mathrm{Ar}\left(100 \mathrm{ml} \mathrm{min}^{-1}\right)$. Inductively coupled plasma mass spectroscopy (ICP-MS) analysis was carried out using iCP QC (Thermo Fisher Scientific, USA) for lithium and titanium content, and elemental analyzer (EuroEA3000) was used for hydrogen and oxygen content. For Ti analysis, as it is difficult to dissolve in $\mathrm{HNO}_{3}$, $\mathrm{HF}$ was used as the solvent, and the test was repeated for three times. X-ray photoelectron spectroscopy (XPS) spectra data were obtained using Escalab 250XI system (Thermo Fisher Scientific, US). Nitrogen adsorption-desorption isotherms were obtained using an Automated vapor sorption analyzer (Autosorb-iQ2-MP (Quanta Chrome)) at 77.4 K under vacuum. The specific surface area was calculated by the Brunauer-Emmett-Teller (BET) method. The morphology, size and crystal structure of the as-prepared samples were characterized by MERLIN VP Compact for scanning electron microscope (SEM), Hitachi-HT7700 for transmission emission microscopy (TEM), JEM-2100F for high-resolution transmission electron microscopy (HRTEM) and selected-area electron diffraction (SAED). Tapping mode atomic force microscopy (AFM) images were collected on a multimode atomic force microscope from Veeco Instruments, employing Olympus microcantilevers (resonance frequency, $300 \mathrm{kHz}$; force constant, $42 \mathrm{~N} \mathrm{~m}^{-1}$ ). ${ }^{1} \mathrm{H}$ solid state magic-angle spinning nuclear magnetic resonance (MAS-NMR) spectra was performed on a Bruker Avance III $(400 \mathrm{MHz})$ spectrometer equipped with a triple channel $2.5 \mathrm{~mm}$ probe and adamantine was used as reference. The data were recorded using a pulse sequence with the spinning speed of $10 \mathrm{~K}$. The samples were prepared and measured after drying over night at $70{ }^{\circ} \mathrm{C}$ in a vacuum. Infrared spectra of the powder samples were measured in diffuse reflectance using a Bruker TENSOR II spectrometer. The samples were measured against a KBr background after purging in inert gas to remove gas-phase water. The depth profiling of LTHs was also analyzed by time-of-flight secondary ion mass spectrometry (TOF-SIMS) using dual ion beams TOF-SIMS (TOF.SIMS 5 ), in which the $\mathrm{Cs}^{+}$ions are for sputtering and the $\mathrm{Bi}_{1}^{+}$ions are for analysis.

Electrochemical measurements. For the electrochemical measurements, the working electrode was prepared by mixing $80 \mathrm{wt} \%$ active material, $10 \mathrm{wt} \%$ Super P, and $10 \mathrm{wt} \%$ poly(vinylidene fluoride) binder in $\mathrm{N}$-methyl-2-pyrrolidinone solvent. The obtained slurry was cast on $16 \mu \mathrm{m}$ thickness $\mathrm{Al}$ foil or $15 \mu \mathrm{m}$ thickness $\mathrm{Cu}$ foil (when $\mathrm{HN}$ was prepared as anode in hybrid supercapacitor and full batteries) via scraper machine and dried at $110^{\circ} \mathrm{C}$ in a vacuum oven for $12 \mathrm{~h}$. Then roll squeezer was used to enhance the contact between material and foil, together with increasing the compaction density. The 2032-coin-type cells were assembled in an argon-filled glove-box using pure lithium foil (for half cells) or commercial activated carbon (YP-50F by Kuraray Chemical Co., LTD for hybrid supercapacitors) or commercial $\mathrm{LiFePO}_{4}$ (for full cells) as counter electrodes, and a microporous membrane (Celgard 2400 , USA) as a separator. $80 \mu \mathrm{L}$ of $1.0 \mathrm{M} \mathrm{LiPF}_{6}$ in a mixture (1:1 volume ratio) of ethylene carbonate (EC) and dimethylcarbonate (DMC) was added as the electrolyte. The mass loading of LTHs anode in this work is $\sim 1.0 \mathrm{mg} \mathrm{cm}^{-2}$. In hybrid supercapacitor device, the AC cathode is about triple the mass of anode; and in the full batteries, the $\mathrm{LiFePO}_{4}$ cathode is about twice the mass of anode. IM6 (Bas-Zahner, Germany) electrochemical workstation was used for 
cyclic voltammetry (CV) and also for electrochemical impedance spectroscopy (EIS) from $10 \mathrm{mHz}$ to $100 \mathrm{kHz}$, with a perturbation of $5 \mathrm{mV}$ applied. For in situ XRD measurements, the home-made coin cell (LS on $\mathrm{Al}$ foil) was discharged/ charged with a constant current at $100 \mathrm{~mA} \mathrm{~g}^{-1}$. All the cells were tested on a LAND 2001A Cell test system and cycled between 1.0-2.5 V (for half cells), 0.2-3.2 V (for hybrid supercapacitors) and $1.2-2.4 \mathrm{~V}$ (for full cells) at room temperature.

Data availability. The relevant data that support the findings of this study are available from the authors upon reasonable request.

Received: 9 November 2016 Accepted: 12 July 2017

Published online: 20 September 2017

\section{References}

1. Dunn, B., Kamath, H. \& Tarascon, J. Electrical energy storage for the grid: a battery of choices. Science 334, 928-935 (2011).

2. Sun, Y. et al. Nanostructured high-energy cathode materials for advanced lithium batteries. Nat. Mater. 11, 942-947 (2012).

3. Chen, Z., Belharouak, I., Sun, Y. K. \& Amine, K. Titanium-based anode materials for safe lithium-ion batteries. Adv. Funct. Mater. 23, 959-969 (2013).

4. Zhu, G. N., Wang, Y. G. \& Xia, Y. Y. Ti-based compounds as anode materials for li-ion batteries. Energy Environ. Sci. 5, 6652-6667 (2012).

5. Wang, L. \& Sasaki, T. Titanium oxide nanosheets: graphene analogues with versatile functionalities. Chem. Rev. 114, 9455-9486 (2014).

6. Zhao, B., Ran, R., Liu, M. \& Shao, Z. A comprehensive review of $\mathrm{Li}_{4} \mathrm{Ti}_{5} \mathrm{O}_{12}$ based electrodes for lithium-ion batteries: the latest advancements and future perspectives. Mat. Sci. Eng. R. 98, 1-71 (2015).

7. Kawamura, T., Okada, S. \& Yamaki, J. Decomposition reaction of $\mathrm{LiPF}_{6}$-based electrolytes for lithium ion cells. J. Power Sources 156, 547-554 (2006).

8. Hong, Z. S. \& Wei, M. D. Layered titanate nanostructures and their derivatives as negative electrode materials for lithium-ion batteries. J. Mater. Chem. A 1, 4403-4414 (2013)

9. Cho, G. Y., Wu, Y. T. \& Ackerman, J. L. Detection of hydroxyl ions in bone mineral by solid-state nmr spectroscopy. Science 300, 1123-1127 (2003).

10. Franks, F., Falk, M. \& Knop, O. Water in Stoichiometric Hydrates. (ed. Franks, F.) 55-113 (Springer US, 1973).

11. Simon, P., Gogotsi, Y. \& Dunn, B. Where do batteries end and supercapacitors begin? Science 343, 1210-1211 (2014).

12. Augustyn, V. et al. High-rate electrochemical energy storage through $\mathrm{Li}^{+}$ intercalation pseudocapacitance. Nat. Mater. 12, 518-522 (2013).

13. Li, J. R., Tang, Z. L. \& Zhang, Z. T. H-titanate nanotube: a novel lithium intercalation host with large capacity and high rate capability. Electrochem. Commun. 7, 62-67 (2005).

14. Wen, P., Ishikawa, Y., Itoh, H. \& Feng, Q. Topotactic transformation reaction from layered titanate nanosheets into anatase nanocrystals. J. Phys. Chem. C 113, 20275-20280 (2009).

15. Chiu, H. et al. Annealing-regulated elimination of residual strain-induced structural relaxation for stable high-power $\mathrm{Li}_{4} \mathrm{Ti}_{5} \mathrm{O}_{12}$ nanosheet anodes. Nano Energy 32, 533-541 (2017).

16. Chen, X. B., Liu, L., Yu, P. Y. \& Mao, S. S. Increasing solar absorption for photocatalysis with black hydrogenated titanium dioxide nanocrystals. Science 331, 746-750 (2011).

17. Wagemaker, M., Borghols, W. J. H. \& Mulder, F. M. Large impact of particle size on insertion reactions. a case for anatase $\mathrm{Li}_{x} \mathrm{TiO}_{2}$. J. Am. Chem. Soc. 129, 4323-4327 (2007).

18. Borghols, W. J. H. et al. Size effects in the $\mathrm{Li}_{4+x} \mathrm{Ti}_{5} \mathrm{O}_{12}$ spinel. J. Am. Chem. Soc. 131, 17786-17792 (2009).

19. Chiu, H. et al. Capacity fade mechanism of $\mathrm{Li}_{4} \mathrm{Ti}_{5} \mathrm{O}_{12}$ nanosheet anode. $A d v$. Energy Mater 7, 1601825 (2016).

20. Liu, H. et al. Capturing metastable structures during high-rate cycling of $\mathrm{LiFePO}_{4}$ nanoparticle electrodes. Science 344, 1252817 (2014).

21. Zhang, X. et al. Rate-induced solubility and suppression of the first-order phase transition in olivine $\mathrm{LiFePO}_{4}$. Nano Lett. 14, 2279-2285 (2014).

22. Malik, R., Zhou, F. \& Ceder, G. Kinetics of non-equilibrium lithium incorporation in $\mathrm{LiFePO}_{4}$. Nat. Mater. 10, 587-590 (2011).

23. Shirpour, M., Cabana, J. \& Doeff, M. Lepidocrocite-type layered titanate structures: new lithium and sodium ion intercalation anode materials. Chem. Mater. 26, 2502-2512 (2014).

24. Maier, J. Nanoionics: ion transport and electrochemical storage in confined systems. Nat. Mater. 4, 805-815 (2005).

25. Ganapathy, S. \& Wagemaker, M. Nanosize storage properties in spinel $\mathrm{Li}_{4} \mathrm{Ti}_{5} \mathrm{O}_{12}$ explained by anisotropic surface lithium insertion. ACS Nano 6 , 8702-8712 (2012).
26. Niu, J. et al. In situ observation of random solid solution zone in $\mathrm{LiFePO}_{4}$ electrode. Nano Lett. 14, 4005-4010 (2014).

27. Wagemaker, M. et al. A kinetic two-phase and equilibrium solid solution in spinel $\mathrm{Li}_{4+x} \mathrm{Ti}_{5} \mathrm{O}_{12}$. Adv. Mater. 18, 3169 (2006)

28. Guo, Y., Hu, J. \& Wan, L. Nanostructured materials for electrochemical energy conversion and storage devices. Adv. Mater. 20, 2878-2887 (2008).

29. Wang, K., Li, X. \& Chen, J. Surface and interface engineering of electrode materials for lithium-ion batteries. Adv. Mater. 27, 527-545 (2015).

30. Wu, Q. et al. Ultrathin anatase $\mathrm{TiO}_{2}$ nanosheets embedded with $\mathrm{TiO}_{2}-\mathrm{B}$ nanodomains for lithium-ion storage: capacity enhancement by phase boundaries. Adv. Energy Mater 5, 1401756 (2014).

31. Magasinski, A. et al. High-performance lithium-ion anodes using a hierarchical bottom-up approach. Nat. Mater. 9, 353-358 (2010).

32. Xia, T. et al. Hydrogenated surface disorder enhances lithium ion battery performance. Nano Energy 2, 826-835 (2013).

33. Kang, B. \& Ceder, G. Battery materials for ultrafast charging and discharging. Nature 458, 190-193 (2009).

34. Fernández-García, M., Martínez-Arias, A., Hanson, J. C. \& Rodriguez, J. A. Nanostructured oxides in chemistry: characterization and properties. Chem. Rev. 104, 4063-4104 (2004).

35. Chen, X. \& Mao, S. S. Titanium dioxide nanomaterials: synthesis, properties, modifications, and applications. Chem. Rev. 107, 2891-2959 (2007).

36. Zhang, F. et al. A high-performance supercapacitor-battery hybrid energy storage device based on graphene-enhanced electrode materials with ultrahigh energy density. Energy Environ. Sci. 6, 1623-1632 (2013).

37. Aoun, B. et al. A generalized method for high throughput in-situ experiment data analysis: an example of battery materials exploration. J. Power Sources $\mathbf{2 7 9}$ 246-251 (2015).

\section{Acknowledgements}

We thank the gracious help of H.Y. Sun, Z.P. Li and X.J. Guo at Tsinghua University, and C. Settens, M.D. Li and L. Sun at MIT. Z.T. acknowledges support by the National Natural Science Foundation of China (No. 51472137) and Ministry of Education of the People's Republic of China (No.20120002110007). J.L. acknowledges support by NSF DMR-1410636 and DMR-1120901. This work was partially supported by the U.S. Department of Energy under Contract DE-AC0206CH11357 from the Vehicle Technologies Office, Department of Energy, Office of Energy Efficiency and Renewable Energy (EERE). This research used resources of the Advanced Photon Source, a U.S. Department of Energy (DOE) Office of Science User Facility operated for the DOE Office of Science by Argonne National Laboratory under Contract No. DE-AC02-06CH11357.

\section{Author contributions}

Z.T. and Ju.L.: Conceived the project. S.W. and W.Q.: Synthesized samples and performed electrochemical tests. S.W., Z.Z., Y.Y., Q.L. Y.R., X.Z., R.X. and Jun.L.: Performed the characterization. All authors analyzed the data and contributed to the discussion. S.W., Z.T. and Ju.L.: Wrote the manuscript.

\section{Additional information}

Supplementary Information accompanies this paper at doi:10.1038/s41467-017-00574-9.

Competing interests: The authors declare no competing financial interests.

Reprints and permission information is available online at http://npg.nature.com/ reprintsandpermissions/

Publisher's note: Springer Nature remains neutral with regard to jurisdictional claims in published maps and institutional affiliations.

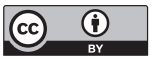

Open Access This article is licensed under a Creative Commons Attribution 4.0 International License, which permits use, sharing, adaptation, distribution and reproduction in any medium or format, as long as you give appropriate credit to the original author(s) and the source, provide a link to the Creative Commons license, and indicate if changes were made. The images or other third party material in this article are included in the article's Creative Commons license, unless indicated otherwise in a credit line to the material. If material is not included in the article's Creative Commons license and your intended use is not permitted by statutory regulation or exceeds the permitted use, you will need to obtain permission directly from the copyright holder. To view a copy of this license, visit http://creativecommons.org/ licenses/by/4.0/.

(C) The Author(s) 2017 